\title{
A Compact ACS-Fed Tri-band Microstrip Monopole Antenna for WLAN/WiMAX Applications
}

\author{
Djafri Kahina $^{1 *}$, Challal Mouloud, ${ }^{1}$, Dehmas Mokrane ${ }^{1}$, Mouhouche Faiza $^{1}$ \\ Aksas Rabia ${ }^{2}$ \\ ${ }^{1}$ Signals and Systems Laboratory, Institute of Electrical and Electronic Engineering, \\ University M'Hamed BOUGARA of Boumerdes, Boumerdes, Algeria. \\ ${ }^{2}$ Ecole Nationale Polytechnique, Department of Electronics, 16000 Algiers, Algeria. \\ *corresponding author, E-mail: k.djafri@univ-boumerdes.dz
}

\begin{abstract}
This paper proposes a novel small asymmetric coplanar strip (ACS) fed tri-band monopole antenna for WLAN and WiMAX applications. To tune and create multiple resonant frequencies, the exciting strip of monopole antenna is connected to two different arms which are a J-shaped directed toward the asymmetric ground plane and an open stub. The proposed monopole antenna with a total size of $14.6 \times 17.5 \mathrm{~mm}^{2}$ is fabricated and tested. The measured results indicate that the antenna has impedance bandwidths for $-10 d B$ return loss reach about $500 \mathrm{MHz}$ (2.01-2.52 $\mathrm{GHz}), 230 \mathrm{MHz}(3.48-3.71 \mathrm{GHz})$ and $1.2 \mathrm{GHz}(5.59-6.72$ $\mathrm{GHz}$ ) which cover widely the $2.4 / 5.8 \mathrm{GHz}$ WLAN bands and the $3.5 \mathrm{GHz}$ WiMAX band. The simulated radiation patterns of the proposed antenna at the three resonant frequencies have a dipole-like radiation pattern in both E-and H-Planes. The compact size, the simple structure and good radiation performances of the proposed antenna makes it well-suited for the intended applications.
\end{abstract}

\section{Introduction}

The rapid size decrease of the electronic devices in the modern communication systems has given rise to an important demand to design miniaturized antennas. Furthermore, more requirements in terms of multiband operation are needed. Consequently, several research works have been conducted to design compact multiband antennas which can support multiple communication applications such as Wireless Local Area Network (WLAN)and Worldwide Interoperability for Microwave Access (WiMAX) technologies. For this issue, many techniques of antenna size reduction have been reported elsewhere; for example, loading the patch with a shorting post [1], using fractal geometries [2], introduction of defected microstrip structure (DMS) [3], using a defected ground structure (DGS) [4] [5] and using shaped patches [6] and [7].

In [6], a compact reconfigurable monopole antenna with a spiral shaped patch was proposed. By embedding microwave switches in three different location in spiral patch, different resonance frequencies can be achieved in diverse states of the switches. Consequently antenna was capable to cover two standard frequency bands for biomedical applica- tions with a compact size of $32 \times 50.3 \mathrm{~mm}^{2}$. A recongurable frequency wide to narrow band antenna has been presented in [7]. The antenna was a combination of a modified circular monopole antenna which produces wide bandwidth and a microstrip slot antenna which produces three resonant frequencies. The antenna size was $60 \times 70 \mathrm{~mm}^{2}$. Although the reported antennas can achieve interesting reconfigurable frequency characteristics but they have large dimensions.

In [8], a rectangular shaped monopole antenna loaded with two split ring resonator (SRR) was proposed for tri-band operation. The antenna covers the WiMAX (3.5/5.5GHZ) and WLAN (2.4/5.2/5.8 GHz) applications. By inserting two SRR slots with adequate dimensions, three operating bands were obtained. Though the reported structure was simple, it has a large size of $832 \mathrm{~mm}^{2}$. In order to downsize the antenna dimensions, the authors in [9] have proposed two miniaturized antennas using difference metamaterial structure. The first antenna operates at three bands covering WiMAX, WLAN and GPS applications with a total size of $30 \times 30 \mathrm{~mm}^{2}$. The second one was designed using interdigital capacitor and spiral inductor operating at $1.06 \mathrm{GHz}, 1.8 \mathrm{GHz}$ and $2.5 \mathrm{GHz}$ with a size including the ground plane of $25 \times 25 \mathrm{~mm}^{2}$. Even though the reported antennas have small patch sizes, they still have relatively large size by including their ground plane. The Authors in [10] presented coplanar waveguide (CPW) fed triband monopole antenna for WLAN/WiMAX applications. By etching an inverted-L slot on the straight strip loaded with a rectangular tuning patch, three distinct wide bands have been achieved. The antenna has an overall size of $36 \times 25 \mathrm{~mm}^{2}$. Although the antenna has a simple structure but it has a relatively large size as for the modern handled devices requirements.

A very attracting technique of miniaturization is to use the asymmetrical coplanar strip (ACS) feeding. This technique is analogous to CPW feed except it has a single lateral ground plane, known by ACS, compared to the dual lateral ground in the CPW. Many ACS-fed antennas have been reported in the aim of size reduction as well as for wide band applications [11]-[13]. In [4], an ACS-fed planar antenna with DGS and DMS for dual-band application was presented. The reported antenna is composed of defect 
in both ground plane and radiating strip. The antenna has an overall dimension of $21 \times 15.35 \mathrm{~mm}^{2}$ and resonates at 3.5 and $5.5 \mathrm{GHz}$. The authors in [14] have proposed a compact uniplanar monopole antenna for tri-band operation. This antenna was loaded with two rectangular SRRs etched on the radiating patch to achieve a tri-band resonant characteristic with a total size of $32 \times 12 \mathrm{~mm}^{2}$. A dual-band meandered ACS-fed monopole antenna for WiLAN/WIMAX applications was presented in [15]. The reported antenna was comprised of an asymmetric ground plane, an ACS-fed structure, and coupled meandered monopole-type of radiating elements that are designed to provide the two desired operation bands with an overall size of $20 \times 12 \mathrm{~mm}^{2}$. However, the reported ACS-fed antennas are still having large size.

In this paper, we propose a very compact ACS-fed triband antenna for WLAN/WiMAX applications. The triband operation is achieved by connecting two arms to the exiting strip of monopole antenna. The shape of the two arms is optimized for both size reduction issue and multiband operation. The first arm has a J-shaped and is directed toward the asymmetric ground plane to further downsize the dimensions of the antenna. The second arm has an open stub shape. The proposed antenna is designed, fabricated and measured. The results show that the antenna has good tri-band characteristics and a dipole-like radiation patterns in both E-and H-planes. Hence, it is suitable for WLAN and WiMAX.

\section{Antenna Structure and Design}

Figure 1 shows the geometry of the proposed ACS-fed triband antenna, fabricated on a $1.63 \mathrm{~mm}$ thick FR-4 substrate with permittivity and loss tangent of 4.4 and 0.02 , respectively. The proposed antenna is composed of an exciting strip connected to two different arms which are a J-shaped directed toward the asymmetric ground plane and an open stub. The overall size of the proposed antenna is only 14.6 $17.5 \mathrm{~mm}(\mathrm{~L} \mathrm{~W})$ including the ground plane. The ACS feed line has a signal strip width of $1.5 \mathrm{~mm}$ and a gap distance of $0.5 \mathrm{~mm}$ between the signal strip and the asymmetric ground plane. After an extensive simulation study with help of a powerful full wave simulator IE3D, the optimized dimensions of the proposed antenna are determined and are listed in Table 1. The radiating structure with ACS-fed line is printed in the same side of the substrate.

The different antennas involved in the evolution study are shown in Figure 2 and their return losses are illustrated in Figure 3. It can be seen from Figure 3 that Antenna 1 presents a simple ASC-fed antenna structure resonating at $5.3 \mathrm{GHz}$. In order to generate a lower resonant mode, a rectangular branch is connected to Antenna 1 to obtain Antenna 2. As can be seen from Figure 3, Antenna 2 operates at two distinct frequency bands extending from $3.68 \mathrm{GHz}$ to 3.86 and from 5.48 to $5.67 \mathrm{GHz}$. In order to construct three different resonant frequencies, the last step is to extend the L-shaped branch to look like as a J-shaped branch (proposed antenna). The final structure operates at three

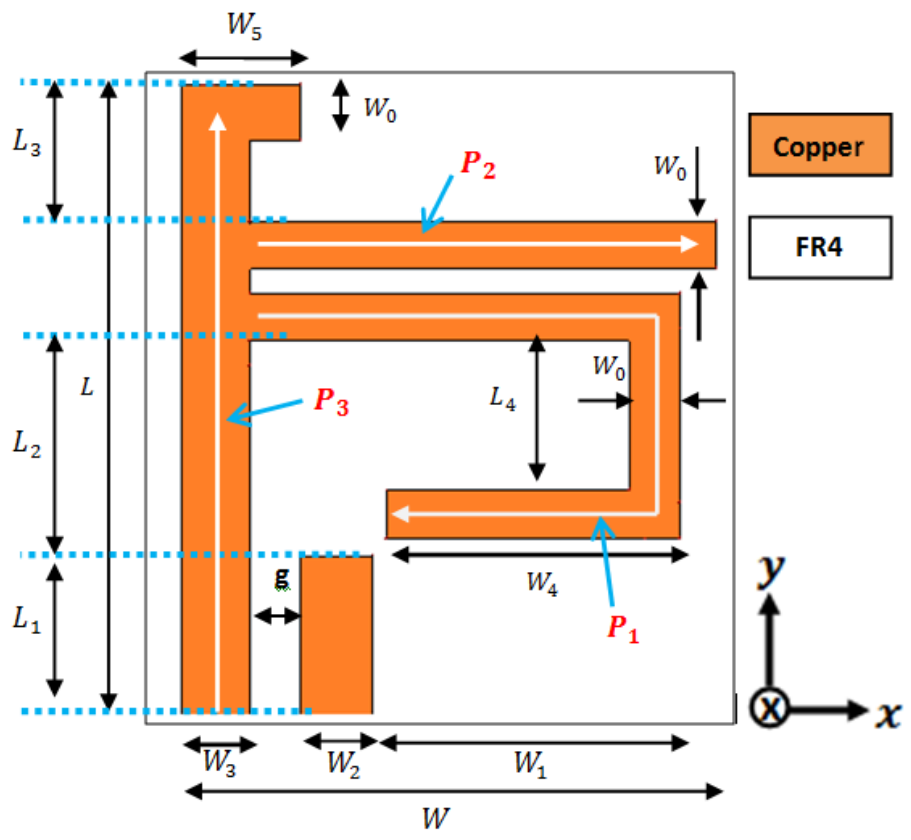

Figure 1: Geometry of the proposed ACS-fed tri-band antenna
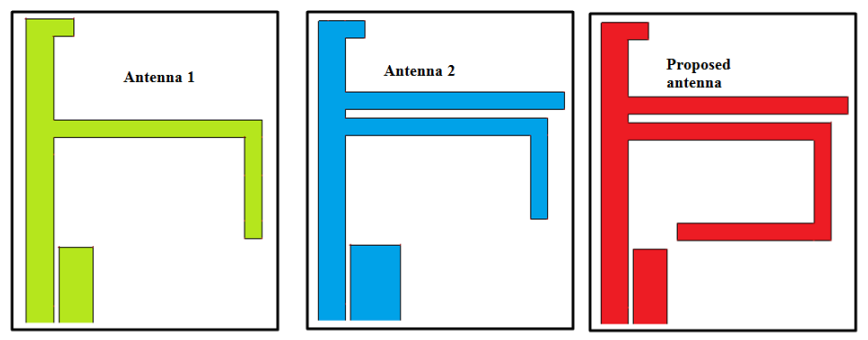

Figure 2: Evolution process of the tri-band monopole antenna

distinct frequency bands ranging from 2.41 to $2.45 \mathrm{GHz}$, from 3.48 to $3.53 \mathrm{GHz}$ and from5.61 to $5.96 \mathrm{GHz}$ as shown in Figure 3 . Accordingly, the proposed tri-band antenna covers the operating bands including WiMAX and WLAN applications.

To more investigate and understand the proposed triband ACS-fed antenna operating mechanism, the average current distributions are simulated at 2.43, 3.5 and 5.765 $\mathrm{GHz}$ as depicted Figure 4. It can be observed that, for the first resonant frequency, the current is mostly concentrated in the J-shaped branch. Thus, the $2.45 \mathrm{GHz}$ can be controlled by changing the length $P_{1}$ which can be calculated by equation 1 [23]. For the second resonant frequency, the maximum current concentration is seen over the open stub. Consequently, the $3.5 \mathrm{GHz}$ can be controlled by tuning the length of the open stub $P_{2}$ and its value can be calculated using equation 2. For the $5.8 \mathrm{GHz}$ frequency, it can be noticed that large concentration of current is recorded at the main branch connected to the feedline, as well as on the other radiating branches due to the strong EM coupling be- 


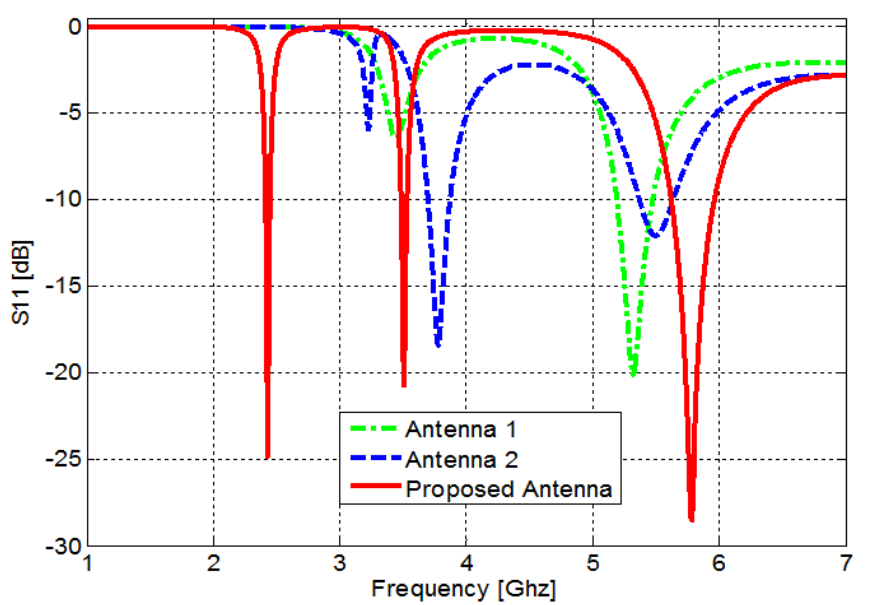

Figure 3: Return losses versus frequency of various ACSfed antenna structures

Table 1: Dimensions of the proposed ACS-fed tri-band antenna (all dimensions in $\mathrm{mm}$ )

\begin{tabular}{cccc}
\hline Parameter & Value $(\mathrm{mm})$ & Parameter & Value $(\mathrm{mm})$ \\
\hline$W$ & 17.5 & $L_{1}$ & 5.4 \\
$W_{0}$ & 1 & $L_{2}$ & 6.3 \\
$W_{1}$ & 9.7 & $L_{3}$ & 4.3 \\
$W_{2}$ & 2 & $L_{4}$ & 4.8 \\
$W_{3}$ & 1.6 & $P_{1}$ & 25.9 \\
$W_{4}$ & 9.1 & $P_{2}$ & 13 \\
$W_{5}$ & 2.8 & $P_{3}$ & 15.7 \\
$L$ & 14.6 & $g$ & 0.5 \\
\hline
\end{tabular}

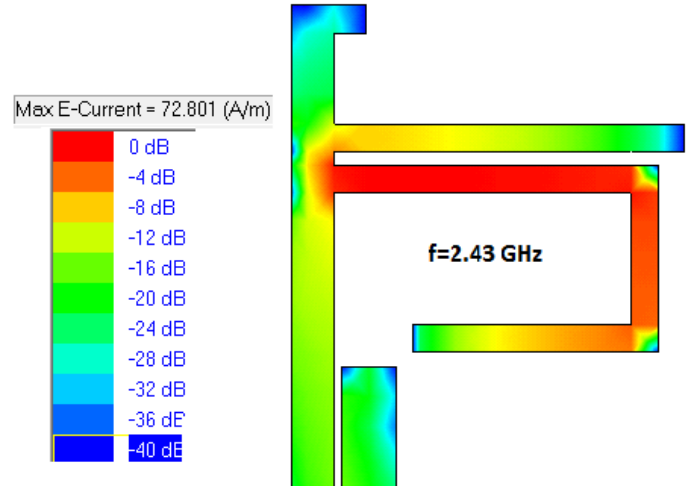

(a)

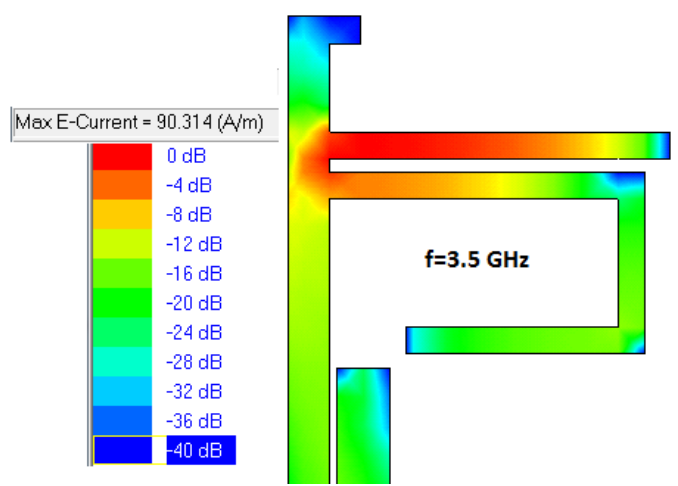

(b)

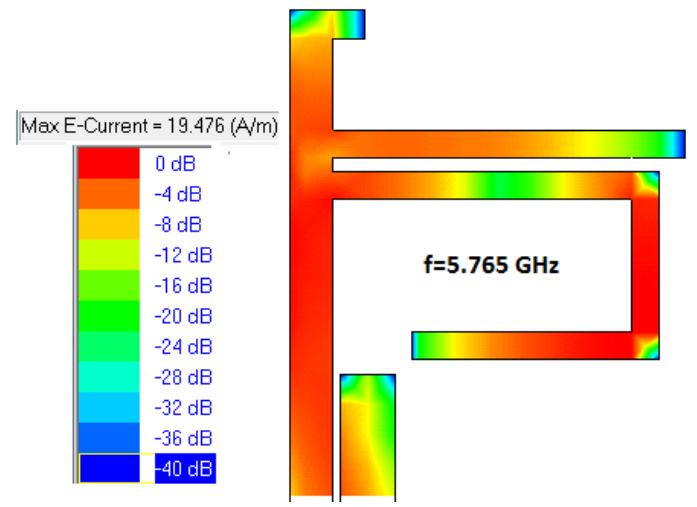

(c)

Figure 4: Average current distributions of the proposed antenna at $2.43,3.5$ and $5.765 \mathrm{GHz}$

tween the branches contributing to the radiation. The expression of the resonant frequency $f_{3}$ is given by equation 3 .

$$
\begin{aligned}
& f_{1}=\frac{c}{3 P_{1} \sqrt{\epsilon_{r, e f f}}} \\
& f_{2}=\frac{c}{4 P_{2} \sqrt{\epsilon_{r, e f f}}} \\
& f_{3}=\frac{c}{2 P_{3} \sqrt{\epsilon_{r, e f f}}}
\end{aligned}
$$




$$
\epsilon_{r, e f f}=\frac{\epsilon_{r}+1}{2}
$$

where $c$ stands for the free space velocity and $\epsilon_{r, \text { eff }}$ is the effective permittivity of the substrate calculated using the equation 4 [4] [23]. For an ACS-fed monopole antenna, It is assumed that half of established the field lies in the substrate and the other one lies in the free space. To further investigate the proposed antenna performance, a parametric study is carried out. As seen previously, in the current distributions study at the three resonant frequencies, the proposed antenna performance is determined mainly by the length of the radiating branches. Figure 5a shows the results obtained through simulation of the return-losses characteristics according to the changes in the J-shaped branch length ( $P 1$ ) while $P_{2}$ and $P_{3}$ are kept constants. As the length increases from 23.5 to $25.9 \mathrm{~mm}$, the frequency shifts toward the lower frequencies.

Furthermore, it can be seen that the reflection coefficient is quite well when P1 is equal to $25.9 \mathrm{~mm}$. The simulated reflection coefficient for different sizes of the open stub branch $\mathrm{P} 2$ is shown in Figure $5 \mathrm{~b}$. It is found that by increasing the length $\mathrm{P} 2$ from 9 to $14 \mathrm{~mm}$, the second resonant frequency shifts toward the lower frequency side. The considered value of P2 is $13 \mathrm{~mm}$ to obtain the centered resonant frequency at $3.5 \mathrm{GHz}$ with good impedance bandwidth. Figure $5 \mathrm{c}$ shows the effect of varying the length of the main branch on the reflection coefficient. It is found that by increasing the length $\mathrm{P} 3$, the upper frequency band shifts toward the lower frequency side. For P3 equal to $15.7 \mathrm{~mm}$, optimum performance is obtained in terms of impedance matching and resonant frequency.

The simulated radiation patterns of the tri-band proposed antenna at the three diverse resonant frequencies namely $2.43 \mathrm{GHz}, 3.5 \mathrm{GHz}$ and $5.8 \mathrm{GHz}$ are shown in Figure 6. It can be seen that the proposed antenna shows a dipole-like patterns in the E-plane (yoz) whereas in the $\mathrm{H}$-plane (xoz), omnidirectional radiation characteristic is achieved for all the three resonant frequencies. Figure 7 shows the 3D radiation patterns of the proposed tri-band ACS-fed antenna at three resonant frequencies. It can be clearly seen that the radiation patterns at each of the three operating frequencies have a doughnut shape (Omni directional in the $x o z$ ) consequently the proposed antenna is well-suited for intended applications.

\section{Fabrication And Measurement}

The proposed tri-band monopole antenna is fabricated and tested. Figure 8 shows the photograph of the fabricated triband antenna. The proposed antenna return loss is measured using a ROHDE SCHARTZ ZNB 20 vector network analyzer (VNA) operating over a frequency range from 10 $\mathrm{kHz}$ to $20 \mathrm{GHz}$.

The measured and simulated return losses of the proposed antenna are shown in Fig. 9. The measured result indicates that the antenna has impedance bandwidths for 10-dB return loss reach about $500 \mathrm{MHz}(2.01-2.52 \mathrm{GHz})$,

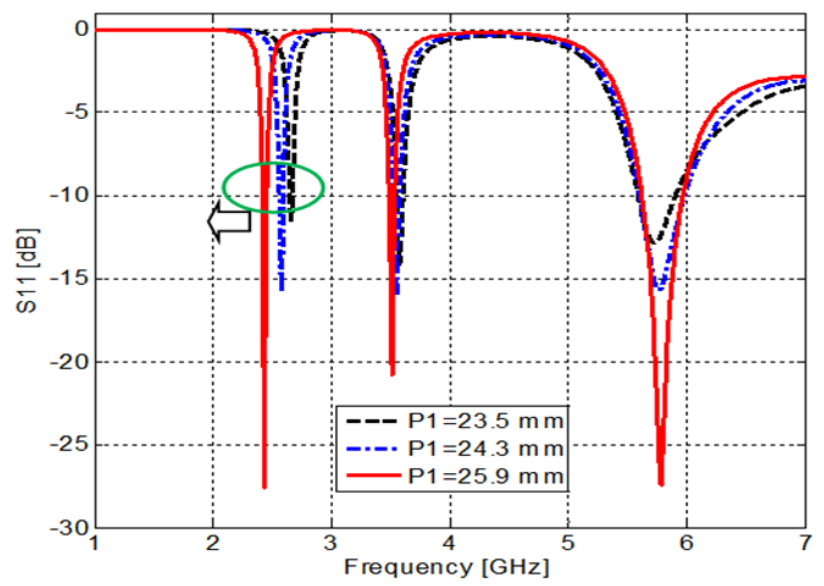

(a) P1 is varied while $\mathrm{P} 2$ and $\mathrm{P} 3$ are kept constants

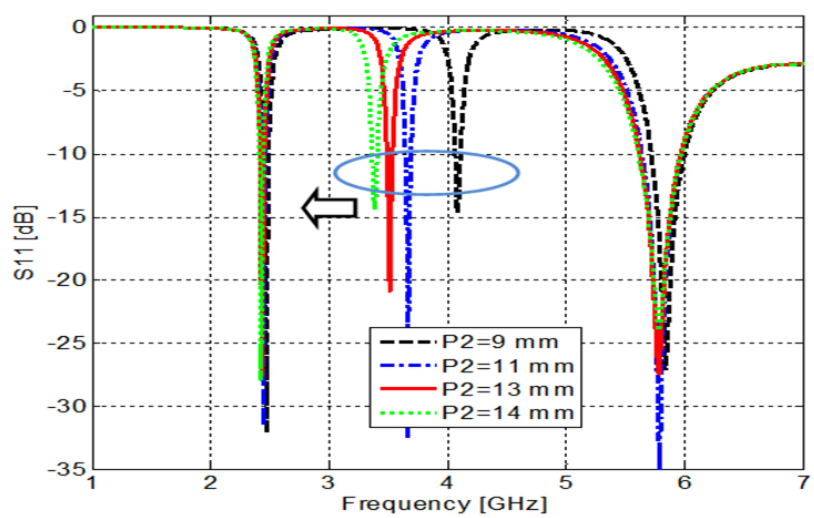

(b) P2 is varied while P1 and P3 are kept constants

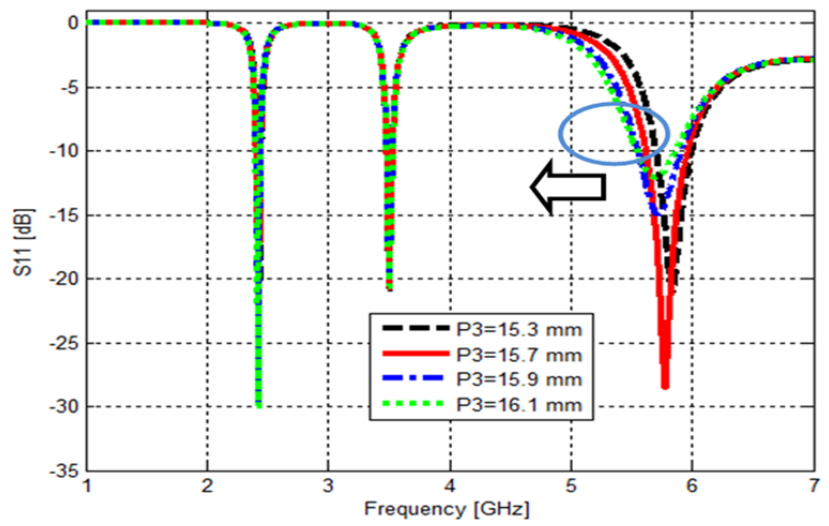

(c) P3 is varied while $\mathrm{P} 1$ and $\mathrm{P} 2$ are kept constants

Figure 5: Return losses of the proposed antenna

$230 \mathrm{MHz}(3.48-3.71 \mathrm{GHz})$ and $1.2 \mathrm{GHz}(5.59-6.72 \mathrm{GHz})$ which can be used for WIFI $2.45 \mathrm{GHz}$, WIMAX $3.5 \mathrm{GHz}$ (3.4-3.69 GHz) and WLAN 5.8 GHz. The slight difference seen between the simulated and the measured results is basically due to the manufacturing tolerances and the uncertainty of the thickness and dielectric relative constant of the substrate added to the quality of the SMA connector which contribute in the discrepancy recorded between the simu- 


\begin{tabular}{ccccc}
\hline Ref. & $\begin{array}{c}\text { Antenna } \\
\text { type }\end{array}$ & $\begin{array}{c}\text { Antenna } \\
\text { size }\left(\mathrm{mm}^{2}\right)\end{array}$ & $\begin{array}{c}\text { Antenna } \\
\text { footprint }\left(\mathrm{mm}^{2}\right)\end{array}$ & $\begin{array}{c}\text { Antenna } \\
\text { purpose }\end{array}$ \\
\hline$[4]$ & Dual-band & $21 \times 15.35$ & 322.35 & $3.4-3.75 \mathrm{GHz}-5.38-5.85 \mathrm{GHz}$ \\
{$[14]$} & Tri-band & $32 \times 12$ & 384 & $2.36-2.70 \mathrm{GHz}, 3.35-2.74 \mathrm{GHz}$ and $5.01-6.12 \mathrm{GHz}$ \\
{$[18]$} & Tri-band & $38 \times 20$ & 760 & $2.32-2.51 \mathrm{GHz}, 3.05-3.95 \mathrm{GHz}$ and $5.4-5.85 \mathrm{GHz}$ \\
{$[19]$} & Tri-band & $17.2 \times 30$ & 516 & $1.752 .0 \mathrm{GHz}, 3.23 .5 \mathrm{GHz}$ and $5.06 .8 \mathrm{GHz}$. \\
{$[20]$} & Tri-band & $21 \times 33$ & 693 & $2.392 .51 \mathrm{GHz}, 3.264 .15$ and $5.06 .43 \mathrm{GHz}$ \\
{$[21]$} & Dual-band & $17.58 \times 30.3$ & 532.6 & $2.16-3.61 \mathrm{GHz}-3.36-3.72 \mathrm{GHz}$ and $4.98-5.87 \mathrm{GHz}$ \\
{$[22]$} & Dual-band & $21 \times 19$ & 399 & $2.24-2.55 \mathrm{GHz}$ and $4.64-5.39 \mathrm{GHz}$ \\
{$[23]$} & Dual-band & $14.75 \times 26$ & 383.5 & $2.2-2.52 \mathrm{GHz}$ and $3.3-4.2 \mathrm{GHz}$ \\
This work & Dual-band & $14.6 \times 17.5$ & 255.5 & $2.01-2.52 \mathrm{GHz}, 3.48-3.72 \mathrm{GHz}$ and $5.59-6.72 \mathrm{GHz}$ \\
\hline
\end{tabular}

Table 2: Comparison between proposed antenna size along with applications bands with other compact antennas

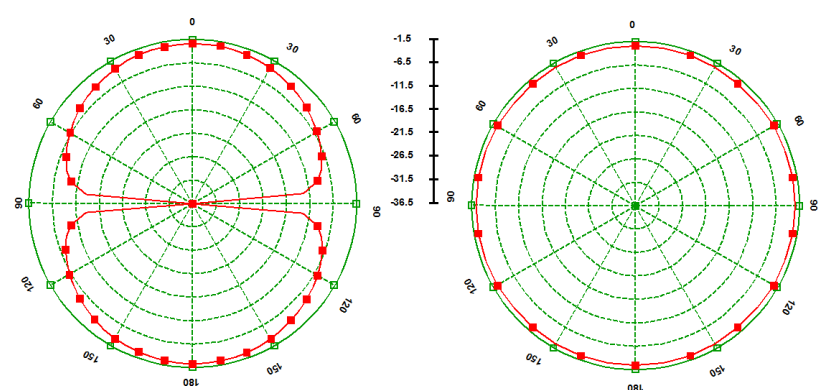

(a)
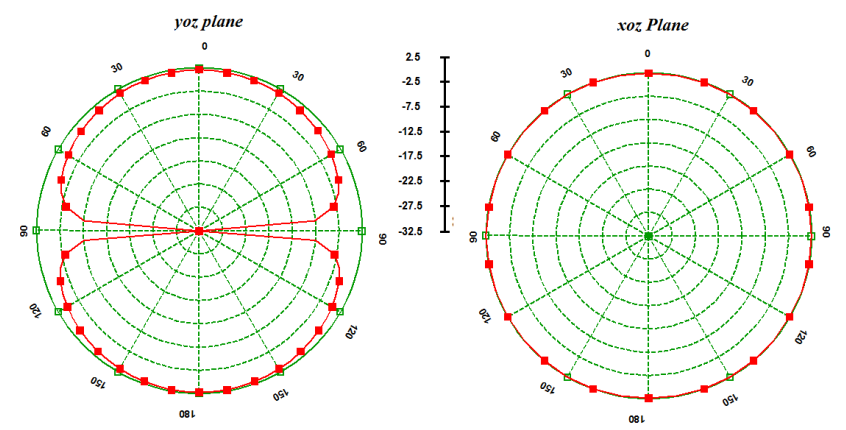

(b)
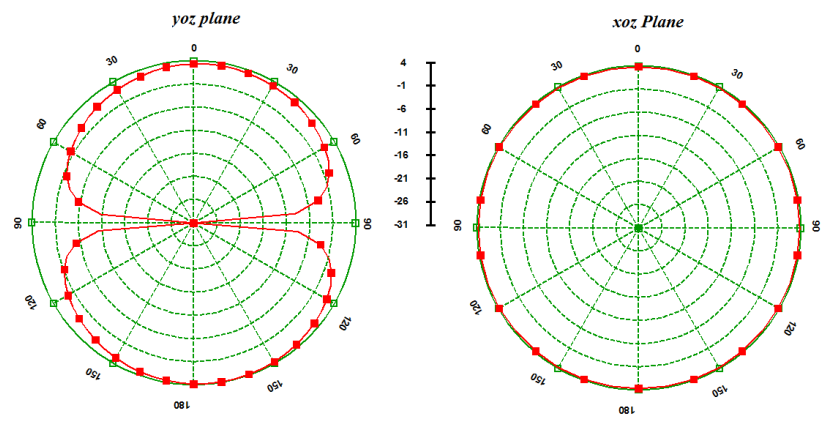

(c)

Figure 6: Radiation patterns at: (a) $2.43 \mathrm{GHz}$, (b) $3.5 \mathrm{GHz}$ and, (c) $5.8 \mathrm{GHz}$

lated and measured results. Furthermore, due to the small size of the antenna the electrical size of the ground plane

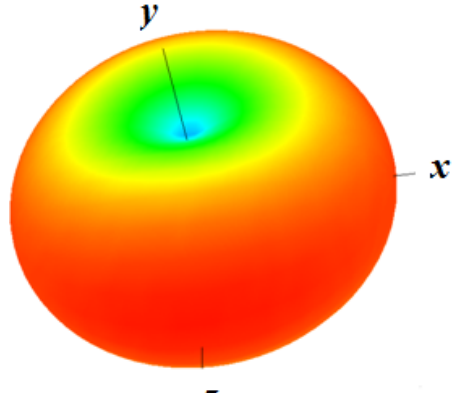

$z$
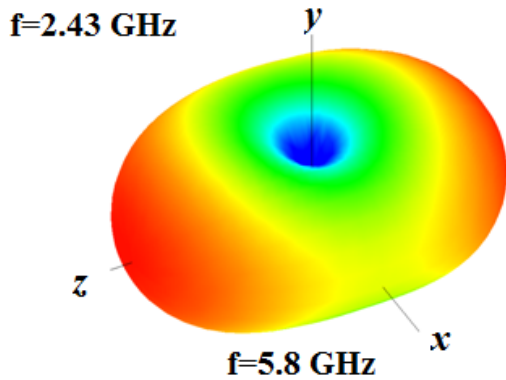

Figure 7: 3D Radiation patterns of the proposed tri-band antenna at different resonant frequencies

became small as compared to the wavelength. In this situation, the SMA connector and a part of the VNA connecting cable act as an additional ground plane [17]. Consequently, the current will flow back from the antenna to the connecting cable.

Comparisons of the proposed overall antenna size along with applications bands with other compact antennas available in literature are illustrated in Table 2. It can be concluded that the proposed antenna achieves significant size reduction. In addition, it has a very simple structure and can be easily integrated to the small handled devices.

\section{Conclusions}

A Compact Tri-Band ACS-fed monopole antenna for wireless communication is designed, fabricated and tested. The proposed antenna has a very simple patch shape, simple feeding structure and compact size of 14.6 x $17.5 \mathrm{~mm}$. The 


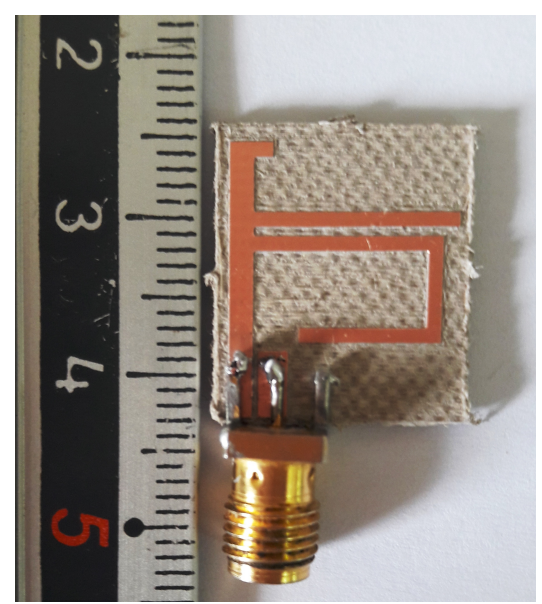

Figure 8: Fabricated tri-band antenna photograph

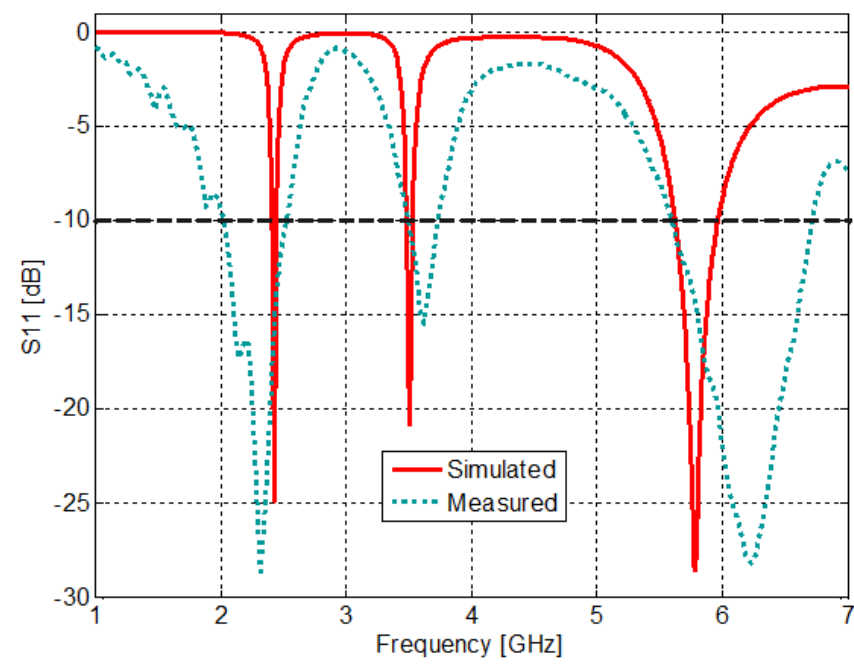

Figure 9: Simulated and measured return losses of the proposed antenna

three resonant frequencies are realized by connecting two different branches to the monopole exciting strip patch. By changing the length of the branches, the operating bands can be easily controlled to the desired frequencies. Measured results demonstrate that the proposed antenna can achieve three desired operating bands suitable for WLAN and WiMAX applications.

\section{References}

[1] H. Kan and R. Waterhouse, Size reduction technique for shorted patches, Electron. Lett., vol. 35, pp. 948949, 1999.

[2] G. Varamini, A. Keshtkar, and M. Naser-Moghadasi, Compact and miniaturized microstrip antenna based on fractal and metamaterial loads with reconfigurable qualification, Int. J. Electron. Commun. (AE), vol. 83, pp. 213-221, 2018.

[3] J. A. TiradoMndez, H. JardnAguilar, F. Itur-
bideSnchez, I. GarciaRuiz, V. MolinaLopez, and R. AcevoHerrera, "A proposed defected microstrip structure (DMS) behavior for reducing rectangular patch antenna size," Microwave Opt. Technol. Lett., vol. 43, pp. 481-484, 2004.

[4] K. A. Ansal and T. Shanmuganantham, "Compact ACS-fed antenna with DGS and DMS for WiMAX/WLAN applications," Int J Microw Wirel Technol, vol. 8, pp. 1095-1100, 2016.

[5] A. Gupta, H. D. Joshi, and R. Khanna, "An X-shaped fractal antenna with DGS for multiband applications," Int J Microw Wirel Technol, vol. 9, pp. 1075-1083, 2017.

[6] Salim M, Pourziad A, A novel reconfigurable spiralshaped monopole antenna for biomedical applications. Prog. Electromagnet. Res. 2015;57:79-84.

[7] Majid HA, Rahim MK, Hamid MR, Ismail MF, Malek F. Frequency reconfigurable wide to narrow band monopole with slotted ground plane antenna. Journal of Electromagnetic Waves and Applications. 2012 Aug 1;26(11-12):1460-9.

[8] D.-L. Jin, T.-T. Bu, J.-S. Hong, J.-F. Wang, and H. Xiong, "A Tri-Band Antenna for Wireless Applications using Slot-Type SRR," Appl. Comput. Electromagnet. Soc. J., vol. 29, 2014.

[9] M. Rahimi, F. B. Zarrabi, R. Ahmadian, Z. Mansouri, and A. Keshtkar, "Miniaturization of antenna for wireless application with difference metamaterial structures," Prog. Electromagnet. Res., vol. 145, pp. 19-29, 2014.

[10] H. Chen, X. Yang, Y.-Z. Yin, J.-J. Wu, and Y.M. Cai, "Tri-band rectangle-loaded monopole antenna with inverted-L slot for WLAN/WiMAX applications," Electron. Lett., vol. 49, pp. 1261-1262, 2013.

[11] S. Soltani, M. Azarmanesh, P. Lotfi, and G. Dadashzadeh, "Two novel very small monopole antennas having frequency band notch function using DGS for UWB application," Int. J. Electron. Commun. (AE), vol. 65, pp. 87-94, 2011.

[12] X.-p. Xiong, Q. Liu, Y. Zhang, and Y.-1. Luo, "Novel ACS-fed monopole antenna for UWB applications with sharp selectivity notched band and additional bluetooth band characteristics," J Electromagnet Wave, vol. 28, pp. 2308-2317, 2014.

[13] Y. Li, W. Li, and Q. Ye, "Miniaturization of asymmetric coplanar stripfed staircase ultrawideband antenna with reconfigurable notch band," Microwave Opt. Technol. Lett., vol. 55, pp. 1467-1470, 2013.

[14] L. Kang, H. Wang, X. H. Wang, and X. Shi, "Compact ACS-fed monopole antenna with rectangular SRRs 
for tri-band operation," Electron. Lett., vol. 50, pp. 1112-1114, 2014.

[15] Y. Li, W. Li, and R. Mittra, "A Compact ACSFED DualBand Meandered Monopole Antenna for Wlan and WiMax Applications," Microwave Opt. Technol. Lett., vol. 55, pp. 2370-2373, 2013.

[16] P. V. Naidu, "Printed V-shape ACS-fed compact dual band antenna for bluetooth, LTE and WLAN/WiMAX applications," Microsyst Technol, vol. 23, pp. 10051015, 2017.

[17] L. Liu, Y. Weng, S. Cheung, T. Yuk, and L. Foged, "Modeling of cable for measurements of small monopole antennas," in Antennas and Propagation Conference (LAPC), 2011 Loughborough, 2011, pp. $1-4$.

[18] X. Ren, S. Gao, and Y. Yin, "Compact triband monopole antenna with hybrid strips for WLAN/WiMAX applications," Microwave Opt. Technol. Lett., vol. 57, pp. 94-99, 2015.

[19] P. V. Naidu and A. Malhotra, "A small asymmetric coplanar strip fed tri-band antenna for PCS/WiMAX/WLAN applications," Microsyst Technol, vol. 23, pp. 13-22, 2017.

[20] W. Hu, Y.-Z. Yin, P. Fei, and X. Yang, ”Compact triband square-slot antenna with symmetrical L-strips for WLAN/WiMAX applications," IEEE Antennas Wireless Propag. Lett., vol. 10, pp. 462-465, 2011.

[21] M. Lamsalli, A. El Hamichi, M. Boussouis, N. Amar Touhami, and T. Elhamadi, "Genetic algorithm optimization for microstrip patch antenna miniaturization," Prog. Electromagnet. Res., vol. 60, pp. 113-120, 2016.

[22] V. Deepu, R. Sujith, S. Mridula, C. Aanandan, K. Vasudevan, and P. Mohanan, "ACS fed printed Fshaped uniplanar antenna for dual band WLAN applications," Microwave Opt. Technol. Lett., vol. 51, pp. 18521856, 2009.

[23] V. Deepu, R. Sujith, S. Mridula, C. Aanandan, K. Vasudevan, and P. Mohanan, "ACS fed printed Fshaped uniplanar antenna for dual band WLAN applications," Microwave Opt. Technol. Lett., vol. 51, pp. 18521856, 2009. 